\title{
Overexpression of p62 is associated with poor prognosis and aggressive phenotypes in osteosarcoma
}

\author{
YAO LU ${ }^{1 *}$, QIAN WANG ${ }^{1 *}$, YONG ZHOU $^{2 *}$, LIANG SUN $^{1}$, BIN HU $^{3}$, HANZHONG XUE $^{1}$, \\ MING LI ${ }^{1}$, KUN ZHANG ${ }^{1}$, CHENG REN $^{1}$, NING DUAN ${ }^{1}$, HONGLIANG LIU ${ }^{1}$, \\ CONGMING ZHANG ${ }^{1}$, ZHONG LI ${ }^{1}$ and TENG MA ${ }^{1}$ \\ ${ }^{1}$ Department of Orthopaedic Surgery, Hong Hui Hospital, Xi'an Jiaotong University College of Medicine, \\ Xi'an, Shaanxi 710054; ${ }^{2}$ Department of Orthopaedic Surgery, Tangdu Hospital, The Fourth Military Medical University, \\ Xi'an, Shaanxi 710038; ${ }^{3}$ Department of Hematology, Xi'an Gao Xin Hospital, Xi'an, Shaanxi 710075, P.R. China
}

Received August 14, 2016; Accepted March 16, 2018

DOI: $10.3892 /$ ol.2018.8579

\begin{abstract}
. p62 (also known as sequestosome 1) protein, is a small regulatory protein that accumulates in autophagy-defective cells that has been demonstrated to be involved in the prognosis and survival of patients with several types of cancer. However, to the best of our knowledge, there have been no such studies for osteosarcoma (OS). In the present study, the expression of p62 in 70 OS samples was determined using immunohistochemistry and its association with various clinicopathological factors was assessed. The results demonstrated that the overexpression of $\mathrm{p} 62$ protein was detected in $77.1 \%$ (54/70) samples, and the expression levels were significantly associated with tumor size $(\mathrm{P}=0.001)$, metastasis $(\mathrm{P}=0.036)$, clinical staging $(\mathrm{P}=0.003)$ and poor prognosis $(\mathrm{P}=0.0058)$. Furthermore, suppression of the $\mathrm{p} 62$ expression by short hairpin RNA interference in F5M2 and F4 cells lines led to decreased cell proliferation, migration and invasion in vitro. These results suggested that increased expression of p62 may be involved in OS progression, and therefore the excess expression of p62 may serve as a novel prognostic biomarker for patients with OS.
\end{abstract}

\section{Introduction}

Osteosarcoma (OS) is the most common primary bone malignancy in children and adolescents, and accounts for $\sim 20 \%$ of all primary bone cancer worldwide $(1,2)$. Although there

Correspondence to: Dr Teng Ma or Dr Zhong Li, Department of Orthopaedic Surgery, Hong Hui Hospital, Xi'an Jiaotong University College of Medicine, 76 Nanguo Road, Xi'an, Shaanxi 710054, P.R. China

E-mail: gukemt@163.com

E-mail: lizhong0607@126.com

${ }^{*}$ Contributed equally

Key words: p62, immunohistochemistry, osteosarcoma, prognosis have been improvements in surgical and multi-agent chemotherapeutics, the long-term survival rate for patients with non-metastatic OS remains at $\sim 60 \%$ (3), whereas, currently, a 5-year survival rate of $30 \%$ is observed in patients with metastatic OS $(1,4)$. Therefore, it is essential to analyze the biological evidence at the molecular level of OS to identify novel prognostic markers and determine the underlying molecular mechanism of OS metastasis.

p62, also known as sequestosome 1, is a multifunctional scaffold protein that regulates cell proliferation, apoptosis, cell survival, inflammation and tumorigenesis through the catabolism of molecules $(5,6)$. The p62 protein is one of the selective substrates of autophagy, localized on the membranes of autophagosomes (7). It has been identified that the accumulation of the p62 protein is variably associated with different types of tumor, including cancer of the prostate, breast, lung, colon and endometrium (8-12). An excessive expression of p62 has been identified to be a cause of poor prognosis in certain tumor types, including prostate and endometrial cancer $(11,12)$. Furthermore, it has been demonstrated that the abnormal expression of p62 may be associated with the activation of oncogenic signaling pathways, including the mammalian target of rapamycin (mTOR), mitogen-activated protein kinase, nuclear factor $\kappa \mathrm{B}(\mathrm{NF}-\kappa \mathrm{B}), \mathrm{Wnt} / \beta$-catenin and potentially other signaling pathways $(7,13)$. Therefore, it is suggested that p62 may function as an oncogene and is involved in poor prognosis in human cancer.

However, the function and clinical significance of p62 has not yet been completely elucidated in OS. In the present study, the expression of p62 was examined and its association with clinicopathological characteristics was investigated in patients with OS.

\section{Materials and methods}

Patients and tumor specimens. The present study was approved by the Ethics Committee of Xi'an HongHui Hospital (Xi'an, China). Either the patients or their guardians provided written informed consent for participation in the study. Formalin-fixed paraffin-embedded tissues were obtained from 85 patients with OS who underwent tumor resection at Xi'an 
HongHui Hospital between March 2007 and November 2009. Patients did not receive preoperative chemotherapy or radiotherapy. However, patients in Enneking stages I, II or III of the disease (14) received postoperative adjuvant chemotherapy [six courses of ifosfamide $\left(2 \mathrm{~g} / \mathrm{m}^{2}\right.$ for 5 days/course), methotrexate $\left(8 \mathrm{~g} / \mathrm{m}^{2}\right.$ for 1 day/course], and Adriamycin $\left(50 \mathrm{mg} / \mathrm{m}^{2}\right.$ for 1 day/course). All patients were followed up for $\geq 3$ years. However, 15 patients were unreachable (17.7\%), and therefore failed to complete follow-up. Consequently, the data presented were for a total of 70 patients (82.3\%) with a median follow-up of 42 months (range, 2-68 months). Of the 70 patients, 22 were female and 48 were male, with a median age of 19 years (range, 8-65 years). A total of 10 osteochondroma specimens were used as normal controls, including 7 male and 3 female patients with a median age of 32 years (range, 15-54 years). All samples were evaluated for diagnosis by two experienced pathologists in Hong Hui Hospital, Xi'an Jiaotong University College of Medicine, (Xi'an, China).

Materials. RPMI-1640 medium was purchased from HyClone (GE Healthcare, Logan, UT, USA). Fetal bovine serum (FBS), penicillin, streptomycin and glutamine were purchased from Gibco (Thermo Fisher Scientific, Inc., Waltham, MA, USA). Immobilon Western horseradish peroxidase chemiluminescence kit and polyvinylidene fluoride membrane were from EMD Millipore (Billerica, MA, USA). Polyclonal antibodies against p62 were purchased from Cell Signaling Technology Inc. (1:2,000; cat. no. 5114, Danvers, MA, USA). Horseradish peroxidase (HRP)-conjugated goat anti-rabbit immunoglobulin and monoclonal antibodies against $\beta$-actin were purchased from Bioworld Technology, Inc. (1:5,000; cat. no. AP0060; St. Louis Park, MN, USA).

Cell culture. Human OS cell sub-lines F4 and F5M2 were established and maintained in the laboratory of Tangdu Hospital (The Fourth Military Medical University, Xi'an, China) as described previously (15). The cells were cultured in RPMI-1640 medium supplemented with 10\% FBS, penicillin $(100 \mathrm{U} / \mathrm{ml})$, streptomycin $(100 \mu \mathrm{g} / \mathrm{ml})$ and glutamine $(2 \mathrm{mM})$ at $37^{\circ} \mathrm{C}$ in a humidified incubator containing $5 \% \mathrm{CO}_{2}$. The human osteoblast hFOB1.19 cell line was purchased from the American Type Culture Collection (Manassas, VA, USA) and cultured similarly in Dulbecco's modified Eagle's medium (Sigma-Aldrich; Merck KGaA, Darmstadt, Germany).

Immunohistochemical analysis. Immunohistochemistry was performed as described in our previous study (16). The anti-p62 antibody was used at a dilution of 1:100. Images were observed at magnification, $x 400$ under a fluorescence microscope. The final scores of expression of p62 were calculated as described previously (16). Each specimen was categorized as follows: $0,(0) ; 1+,(1-3) ; 2+,(4-8)$; and 3+, (9-12). Scores of 0-3 and 4-12 were designated low and high expression, respectively.

Short hairpin RNA (shRNA) targeting p62. The lentiviruses with shRNA targeting p62 (5'-TCGAGGAAATGGGTCCAC CAGGAATTCAAGA-3') and shRNA negative control were purchased from Hanbio Biotechnology Co., Ltd. (Shanghai, China). F5M2 and F4 cells were transfected with the lentiviruses at a multiplicity of infection of 100 using TransDux transfection reagent (System Biosciences, Palo Alto, CA, USA). Stable p62-knockdown OS cells (F5M2-shp62 cells or F4-shp62 cells) were selected using $3 \mathrm{mg} / \mathrm{ml}$ puromycin (Hanbio Biotechnology Co., Ltd.) and confirmed using the reverse transcription-quantitative polymerase chain reaction (RT-qPCR) and western blotting. These stable knockdown cells and controls (Green Fluorescent Protein (GFP)-F5M2 cells or GFP-F4 cells) were used for subsequent experiments following transfection for $48 \mathrm{~h}$.

$R T-q P C R$. F5M2 and F4 cells, as well as OS adjacent healthy tissue, were harvested and lysed with TRIzol (Invitrogen; Thermo Fisher Scientific, Inc.). All samples were sent to UcallM Biotech Company (Wuxi, China) for subsequent experimental procedures. The Revert Aid First-Strand RT-PCR kit (Invitrogen: Thermo Fisher Scientific, Inc.) was used to synthesize cDNA from $500 \mathrm{ng}$ total RNA. Then $2 \mu \mathrm{l}$ cDNA was amplified in $20 \mu 1$ reaction mixture containing $10 \mu 1$ of SYBR Green PCR mix (Invitrogen: Thermo Fisher Scientific, Inc.) according to the manufacturer's protocol. The following thermocycling conditions were used: $5 \mathrm{~min}$ at $95^{\circ} \mathrm{C}$, followed by 40 cycles of $10 \mathrm{sec}$ at $95^{\circ} \mathrm{C}$ and $30 \mathrm{sec}$ at $60^{\circ} \mathrm{C}$. The p62 gene expression was calculated using the $2^{-\Delta \Delta C q}$ method (17). The primers used for amplification were as follows: Human p62 forward, 5'-TGAGGAACAGATGGA GTCGG-3' and reverse, 5'-GAGATGTGGGTACAAGGC AG-3'; human GAPDH forward, 5'-ACCCACTCCTCCACC TTTG-3' and reverse, 5'-CACCACCCTGTTGCTGTAG-3'. All experiments were performed in triplicate and repeated at least three times independently.

Cell counting kit-8 (CCK-8) assay. F5M2-shp62, GFP-F5M2, F4-shp62 and GFP-F4 cells were seeded into 96-well plates at a density of 2,000 cells/well. After $24 \mathrm{~h}$ of incubation at $37^{\circ} \mathrm{C}$ in $5 \% \mathrm{CO}_{2}, 10 \mu \mathrm{l} /$ well CCK-8 reagent (Dojindo Molecular Technologies, Inc., Kumamoto, Japan) was added to one plate, which was incubated for $2 \mathrm{~h}$ at $37^{\circ} \mathrm{C}$ and measured using a microplate reader (Thermo Fisher Scientific, Inc.) at $490 \mathrm{~nm}$. Each experiment was repeated three times independently.

Transwell migration and invasion assays. The Transwell migration and invasion assays were performed as in our previous study (18). The migratory and invasive potential of cells were assessed using a Transwell (Corning Inc., Corning, NY, USA) inserts only or using inserts pre-coated with $50 \mu \mathrm{l}$ of BD Matrige ${ }^{\mathrm{TM}}$ Basement Membrane Matrix (1:3 dilution, BD Biosciences, Franklin Lakes, NJ, USA). The upper chambers were seeded with $1 \times 10^{4}$ cells suspended in serum-free RPMI-1640 medium, and the lower chambers were filled with complete RPMI-1640 medium with $10 \%$ FBS $(0.6 \mathrm{ml} /$ well). The invasion was evaluated after $16 \mathrm{~h}$ of incubation at $37^{\circ} \mathrm{C}$. The migration was assessed after $24 \mathrm{~h}$ of incubation. Invasion and migration were examined under a light microscope (Nikon Eclipse 80i; Nikon Corporation, Tokyo, Japan) at a magnification, x200 in five randomized fields. All experiments were independently repeated three times.

Western blot analysis. Cellular lysates were prepared in chilled radioimmunoprecipitation assay lysis buffer (Cell Signaling 
Table I. Expression levels of p62 in osteosarcoma and osteochondroma specimens.

\begin{tabular}{lrrrr}
\hline & \multicolumn{3}{c}{ p62 expression } & \\
\cline { 3 - 4 } Group & $\mathrm{n}$ & \multicolumn{1}{c}{+++++} & \multicolumn{1}{c}{$-/+$} & P-value \\
\hline Osteosarcoma & 70 & $54(77.1 \%)$ & $16(22.9 \%)$ & $<0.01$ \\
Osteochondroma & 20 & $6(30.0 \%)$ & $14(70.0 \%)$ & \\
\hline
\end{tabular}

Each specimen was scored as follows: $0,(0) ; 1+,(1-3) ; 2+,(4-8)$; and $3+,(9-12)$.

Table II. Association between p62 expression and clinicopathological data in patients with osteosarcoma.

\begin{tabular}{|c|c|c|c|c|}
\hline \multirow[b]{2}{*}{ Variable } & \multirow[b]{2}{*}{$\mathrm{n}$} & \multicolumn{2}{|c|}{ p62 expression } & \multirow[b]{2}{*}{ P-value } \\
\hline & & High & Low & \\
\hline Total & 70 & 54 & 16 & \\
\hline Sex & & & & 0.551 \\
\hline Male & 48 & 38 & 10 & \\
\hline Female & 22 & 16 & 6 & \\
\hline Age, years & & & & 0.816 \\
\hline$\geq 20$ & 16 & 12 & 4 & \\
\hline$<20$ & 54 & 42 & 12 & \\
\hline Tumor size, $\mathrm{cm}^{2}$ & & & & $0.001^{\mathrm{a}}$ \\
\hline$<50$ & 20 & 16 & 12 & \\
\hline$\geq 50$ & 27 & 38 & 4 & \\
\hline Histology & & & & 0.355 \\
\hline Osteoblastic & 31 & 25 & 6 & \\
\hline Chondroblastic & 8 & 4 & 4 & \\
\hline Fibroblastic & 10 & 8 & 2 & \\
\hline Telangiectatic & 15 & 12 & 3 & \\
\hline Mixed & 6 & 5 & 1 & \\
\hline Metastasis & & & & $0.036^{\mathrm{a}}$ \\
\hline Yes & 29 & 26 & 3 & \\
\hline No & 41 & 28 & 13 & \\
\hline Clinical stage & & & & $0.003^{\mathrm{a}}$ \\
\hline I/IIA & 17 & 9 & 8 & \\
\hline IIB & 24 & 19 & 5 & \\
\hline III & 29 & 26 & 3 & \\
\hline
\end{tabular}

${ }^{\mathrm{a}} \mathrm{P}<0.05$.

Technology, Inc.), and the protein concentrations were determined using a BCA protein assay kit (Pierce; Thermo Fisher Scientific, Inc.). Proteins (10 $\mu \mathrm{l})$ were loaded and separated by electrophoresis on $10 \%$ SDS-polyacrylamide gels at $110 \mathrm{~V}$ for $2 \mathrm{~h}$. Following electrophoresis, the SDS-PAGE gels were transferred electronically to polyvinylidene difluoride (PVDF) membranes (Bio-Rad Laboratories, Inc., Hercules, CA, USA). PVDF membranes were blocked using a solution containing
$5 \%$ skimmed milk and incubated overnight at $4{ }^{\circ} \mathrm{C}$ with the following antibodies: Anti-p62 and anti- $\beta$-actin $(1: 1,000)$. Following washing with Tris-buffered saline with Tween-20, the membranes were incubated for $1 \mathrm{~h}$ at room temperature with HRP-conjugated goat anti-rabbit immunoglobulin and monoclonal antibodies against $\beta$-actin. Reactive proteins were visualized using an Immobilon western horseradish peroxidase chemiluminescence kit (EMD Millipore, Billerica, MA, USA). Relative p62 expression levels as analyzed using ImageJ software version 1.47 (National Institutes of Health, Bethesda, MD, USA).

Statistical analysis. The statistical analyses were carried out using GraphPad Prism software (version 5.0; GraphPad Software Inc., La Jolla, CA, USA). The immunohistochemistry data were analyzed using the $\chi^{2}$ test. Survival data were analyzed using the Kaplan-Meier with log-rank tests estimator method. The RT-qPCR, western blot analysis, inhibitor migration assay and inhibitor invasion assay results were analyzed by one-way analysis of variance. All other data were analyzed using a two-sided Student's t-test. The data are presented as the mean \pm standard deviation. $\mathrm{P}<0.05$ was considered to indicate a statistically significant difference.

\section{Results}

Clinicopathological features and prognostic implications of p62 expression. Using immunohistochemistry, it was identified that the p62 was distributed in the cytoplasm and perinuclear membrane of the OS cells (Fig. 1A and B). Compared with osteochondroma samples, the expression rate of p62 was significantly increased in OS (Table I; Fig. 1C). The increased expression of p62 protein was observed in 54/70 samples (77.14\%) and was identified to be significantly associated with tumor size $(\mathrm{P}=0.001)$, metastasis $(\mathrm{P}=0.036)$ and clinical staging $(\mathrm{P}=0.003)$ (Table II). These patients were also significantly associated with a decreased overall survival time $(\mathrm{P}=0.0058$; Fig. 1D).

Human OS cell lines F5M2 and F4 express p62. RT-qPCR results identified that the expression level of p62 mRNA was highest in the human OS cell lines F5M2 and F4 and lowest in the human osteoblastic cell line hFOB1.19 (P<0.001; Fig. 2A). The expression level of $\mathrm{p} 62$ protein in these cell lines was then assessed by western blotting. The results demonstrated that OS cells (F5M2 and F4) expressed increased levels of p62 protein compared with osteoblastic cells (hFOB1.19) (Fig. 2B), which was identified to be a significant difference (Fig. 2C).

p62 knockdown decreases the proliferative capacity of F5M2 and F4 cells. A CCK-8 cell proliferation assay was used to examine the effect of $\mathrm{p} 62$ inhibition on the in vitro proliferative capacity of F5M2 and F4 cells. p62 expression was stably downregulated by lentiviral-mediated shRNA. Compared with the controls (GFP-F5M2 and GFP-F4), the p62 expression was efficiently decreased in the stable p62-inhibited cells (F5M2-shp62 and F4-shp62) (Fig. 2D), which was identified to be a significant difference (Fig. 2E). Subsequently, the CCK-8 cell proliferation assay demonstrated that stable p62 knockdown decreased the proliferation of F5M2 (P<0.01; Fig. $3 \mathrm{~A})$ 

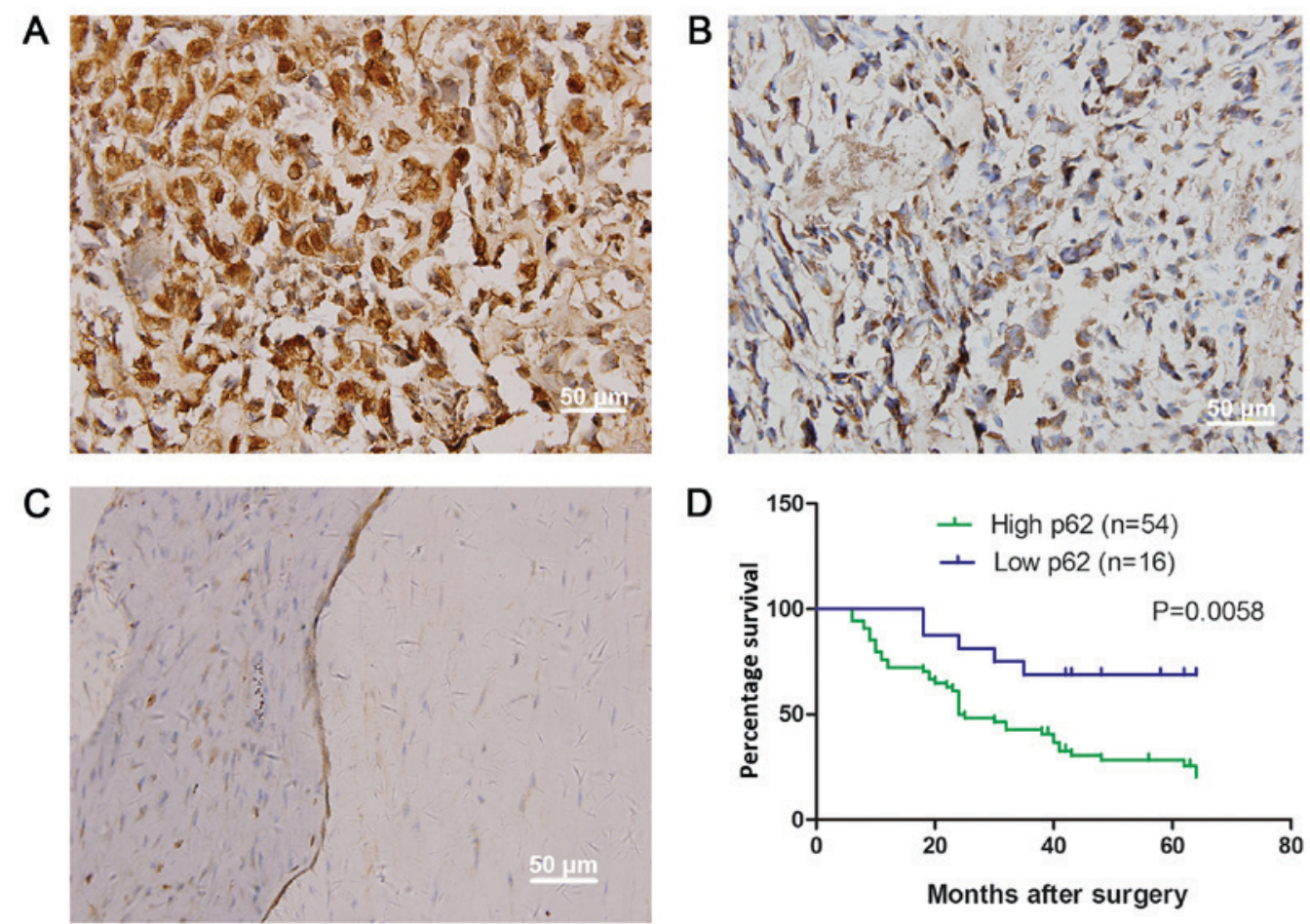

Figure 1. Expression of p62 in osteosarcoma and osteochondroma (magnification, x400), and prognostic implication. (A) High expression of p62 in osteosarcoma; (B) low positive expression of p62 in osteosarcoma; (C) negative expression of p62 in osteochondroma tissues; (D) overall survival curves of 70 patients with osteosarcoma according to p62 expression. Survival curves of the 54 and 16 patients with osteosarcoma that exhibited high (green) and low (blue) expression of $\mathrm{p} 62$.

\section{A}

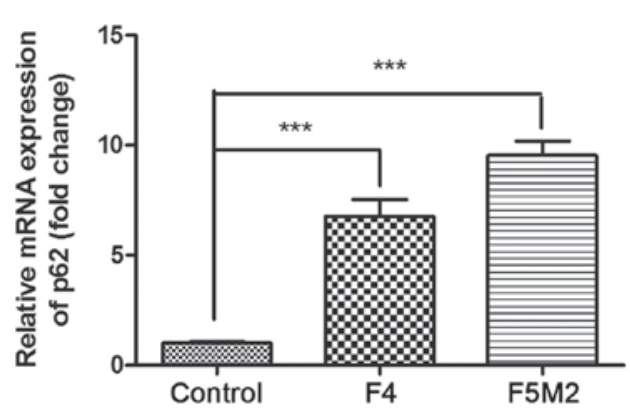

B
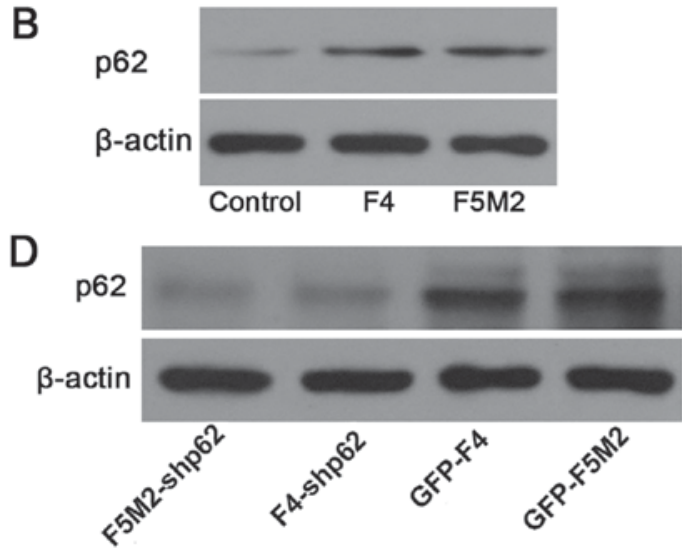

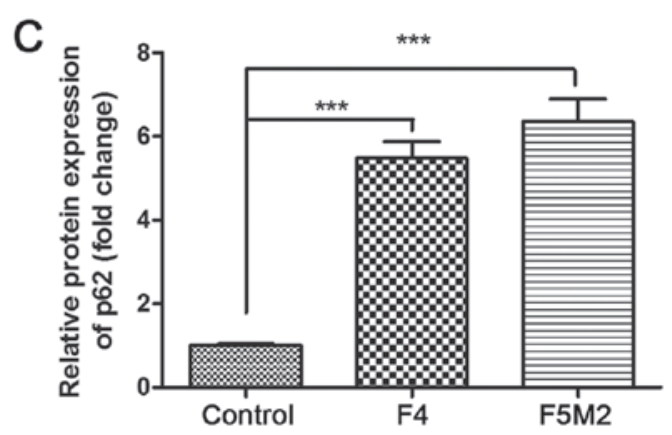

$\mathrm{E}$

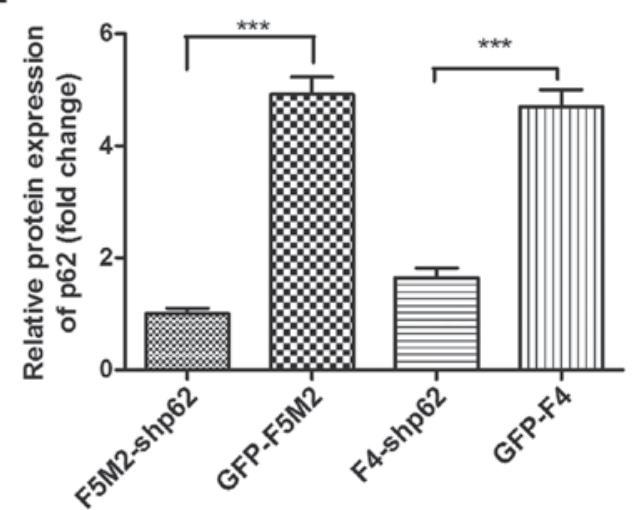

Figure 2. p62 expression in osteosarcoma cells and shRNA-mediated suppression. (A) p62 mRNA expression in F5M2 and F4 human osteosarcoma cells and control hFOB1.19 normal human osteoblast cells detected using the reverse transcription-quantitative polymerase chain reaction. All osteosarcoma cells expressed increased p62 mRNA levels compared with the normal osteoblasts. (B) Western blotting results demonstrating p62 protein expression in F5M2 and F4 osteosarcoma cells and control hFOB1.19 normal human osteoblast cells. (C) Relative p62 expression levels as analyzed using ImageJ software. All osteosarcoma cells expressed an increased amount of p62 protein compared with normal osteoblasts. (D) p62 protein detection by western blotting following shRNA silencing. (E) p62 relative protein expression levels analyzed using ImageJ. p62 expression was efficiently suppressed by shRNA in F5M2 and F4 cells. ${ }_{* * * *} \mathrm{P}<0.001$. Data are presented as the mean \pm standard deviation of three independent experiments. sh, short hairpin. 

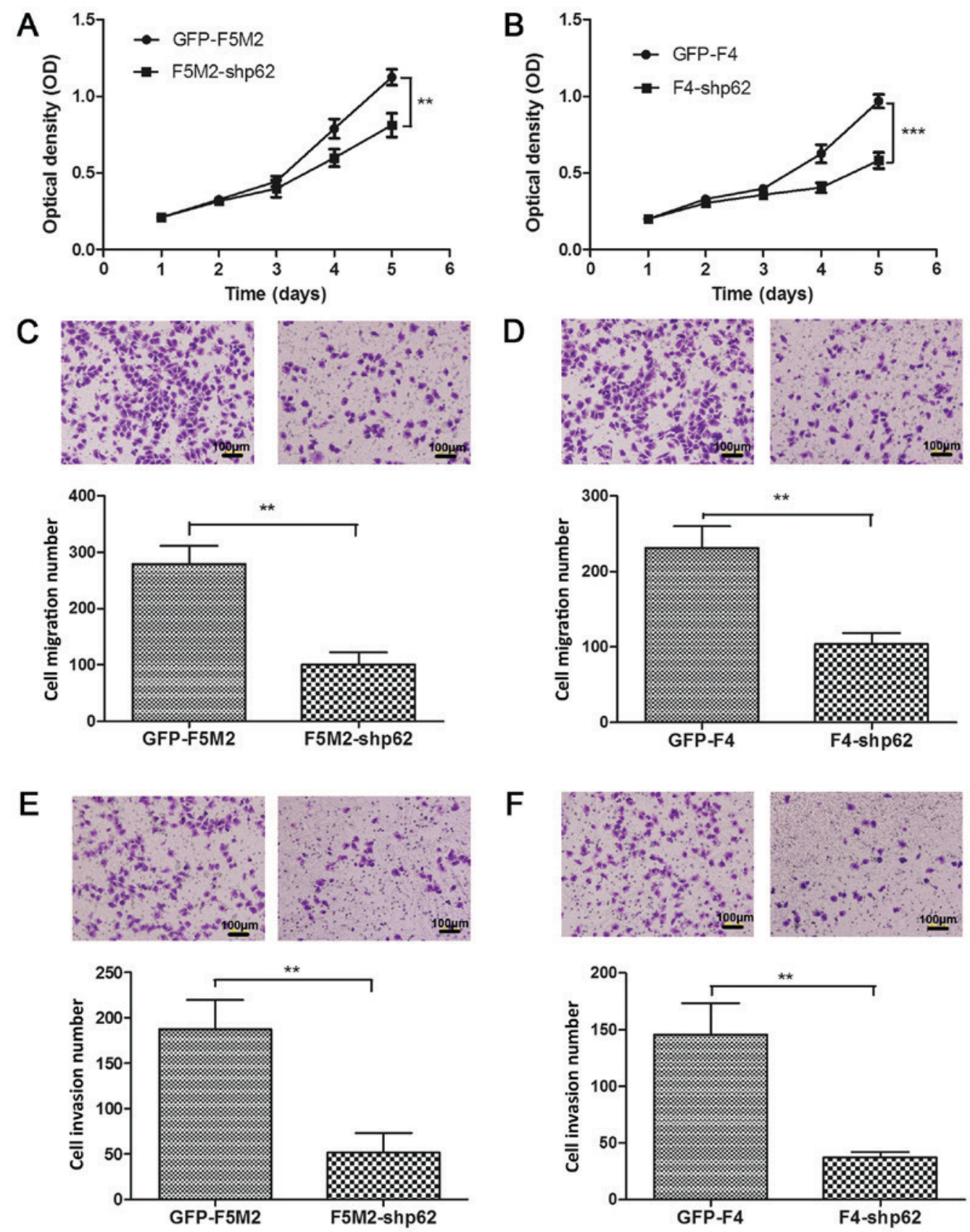

Figure 3. Suppressing p62 expression inhibited proliferation, migration, and invasion. (A) CCK-8 assay for the GFP-F5M2 and F5M2-shp62 cells. The proliferation rate of the F5M2-shp62 cells was significantly decreased compared with that of the GFP-F5M2 cells. (B) CCK-8 assay for the GFP-F4 and F4-shp62 cells. The proliferation rate of the F4-shp62 cells was significantly decreased compared with that of the GFP-F4 cells. (C) Migration assay with GFP-F5M2 and F5M2-shp62 cells. The migratory capacity of the F5M2-shp62 cells was significantly decreased compared with that of the GFP-F5M2 cells. (D) Migration assay with GFP-F4 and F4-shp62 cells. The migratory capacity of the F4-shp62 cells was significantly decreased compared with that of the GFP-F4 cells. (E) Invasion assay with GFP-F5M2 and F5M2-shp62 cells. The invasion rate of the F5M2-shp62 cells was significantly decreased compared with that of the GFP-F5M2 cells. (F) Invasion assay with GFP-F4 and F4-shp62 cells. The invasion rate of the F4-shp62 cells was significantly decreased compared with that of the GFP-F4 cells (vs. F4-shp62). Data are presented as the mean \pm standard deviation of three independent experiments. ${ }^{* *} \mathrm{P}<0.01$; **** $\mathrm{P}<0.001$. CCK-8, Cell Counting kit-8; sh, short hairpin.

and F4 cells $(\mathrm{P}<0.001$; Fig. 3B) compared with their respective controls.

p62 knockdown decreases the migration and invasion of F5M2 and F4 cells. The migration assay results demonstrated that p62 inhibition significantly decreased the migratory ability of F5M2 cells $(\mathrm{P}<0.01$; Fig. $3 \mathrm{C})$ and F4 cells $(\mathrm{P}<0.01$; Fig. 3D) when compared with the corresponding control groups. The invasion assay results revealed that p62 inhibition significantly decreased the invasive ability of F5M2 (P<0.01; Fig. 3E) and F4 cells $(\mathrm{P}<0.01$; Fig. 3F).

\section{Discussion}

The results of the present study demonstrated that the increased expression of p62 protein was significantly associated with tumor size, metastasis and clinical staging in human OS, and may be used as a prognostic factor. However, patients with 
increased expression of p62 protein were identified to be significantly associated with decreased overall survival times compared with those with low p62 expression. To the best of our knowledge, this present study is the first to investigate the clinical significance of p62 expression in OS.

The abnormal expression of p62 detected in a variety of tumors, including breast, prostate, lung, liver and oral cancer, serves an active function in tumorigenesis and metastasis $(12,19,20)$. To determine the $\mathrm{p} 62$ protein levels in prostate cancer, Burdelski et al (11) used immunohistochemistry to assess 7,822 prostate cancers and found that p62 stained in $73 \%(5,716 / 7,822)$. In addition, the protein was markedly associated with high Gleason grade, positive nodal status, advanced pathological tumor stage and positive resection margin (12). Therefore, the accumulation of p62 may be considered as a predictor of the detrimental prognostic behavior of prostate cancer (12). The expression of p62 is substantially weak in normal gastric tissue samples, whereas increased cytoplasmic and nuclear levels are detected in gastric cancer (21). The immunohistochemical analysis of the present study indicated increased expression p62 protein in $77.14 \%$ (54/70) of the analyzed OS samples.

Previous studies have demonstrated that the autophagy system constantly degraded the p62 protein $(22,23)$, whereas other studies indicated that p62 expression is regulated at the transcriptional level $(24,25)$. However, the specific function of p62 in tumors remains unclear, and it has been demonstrated that increased p62 mRNA expression is associated with increased p62 protein expression in the oral squamous cell carcinoma (19). In the present study, it was demonstrated that the p62 mRNA and protein levels were upregulated in human F5M2 and F4 OS cells, suggesting that the protein regulation occurred at the transcriptional and translational levels.

In order to investigate the function of p62 in tumor cell proliferation, migration and invasion, stable p62 knockdown cell lines were established using specific shRNA. Using a CCK-8 assay, p62 knockdown was determined to suppress the proliferation of F5M2 and F4 OS cells. Furthermore, the migration and invasion assays demonstrated that p62 knockdown decreased the migration and invasion of F5M2 and F4 cells in vitro. Thus, increased p62 expression increased the proliferation, migration and invasion of OS cells in vitro. Previous studies have also established that the p62 protein functions as a hub for various signal transduction pathways for cell survival and cell death (20). The overexpression of p62 has been identified to promote tumor cell survival via impairment of the NF- $\kappa \mathrm{B}$ signaling pathway (26). The NRF2-Keap1 pathway consisted of the transcription factor nuclear factor erythroid 2-related factor 2 (NRF2), and the cytoplasmic contact protein Keap1. NRF2 is a central regulator of the cellular antioxidant stress reaction. Furthermore, NRF2 is able to regulate the expression of several detoxification enzymes and a series of antioxidative protein genes, thereby serving a major function in antitumor mechanisms (6). Under normal conditions, NRF2 was degraded by the ubiquitin-proteasome pathway through interaction with Keap1. When exposed to the pro-electronic reagent, reactive oxygen species and nitric oxide, Keap1 is activated, leading to NRF2 heterodimerization and translocation to the nucleus (6). Subsequently, the nuclear NRF2 is able to induce a series of transcription cell protective genes (6). The p62 protein is able to directly interact with Keap1 of NRF2, and the excessive expression of p62 is able to continuously stimulate NRF2, which is hypothesized to lead to tumor progression (27). Aberrant mitosis often leads to tumor occurrence (28). The active association of cyclin-dependent kinase (CDKs) with cell cycle proteins is the key to an orderly cell cycle (28). The lack of cell cycle proteins or the presence of CDK inhibitor leads to cell cycle arrest and cell death (29). The study of Linares et al (30) elucidated the expression of p62 protein in different cells at various stages of the cell cycle, and identified that the protein had been phosphorylated in the early stage of mitosis. Following inhibition of the activity of CDKs, the $\mathrm{p} 62$ protein was phosphorylated at $\mathrm{Thr}^{269}$ and $\mathrm{Ser}^{272}$, suggesting that it may be involved in the mitotic division of cells (30). In addition, it has been demonstrated that p62 is able to activate the mTOR signaling pathway to regulate cell growth and autophagy (31).

There were several limitations to the present study. First, the study was primarily limited by the number of patient samples. Secondly, despite osteochondroma as the control group, the study lacked normal tissue as the control group. Finally, the regulatory mechanism of p62 in OS was not elucidated. Further studies with larger patient populations involving normal tissue, mechanism of p62 in OS, and animal experiment are essential to assess p62 more accurately as a therapeutic target for OS.

In summary, the results of the present study demonstrated that p62 was upregulated in human OS. Furthermore, the overexpression of $\mathrm{p} 62$ protein is associated with poor survival rates in patients with OS. Additionally, p62 may be involved in osteosarcoma progression; however, further studies are a prerequisite for understanding the significance of increased expression of p62 in order to develop specific and comprehensive treatments.

\section{Acknowledgments}

Not applicable.

\section{Funding}

The present study was supported by the Project of Science and Technology Department of Shaanxi Province (grant nos. 2015SF116, 2015SF110 and 2013K14-02-12).

\section{Availability of data and materials}

All data generated or analyzed during this study are included in this published article.

\section{Authors' contributions}

$\mathrm{HX}, \mathrm{ML}$ and $\mathrm{KZ}$ analyzed and interpreted the patient data. LS and BH performed the immunohistochemical analysis, YL, QW and YZ performed RT-qPCR, western blot, CCK-8 assay and Transwell and were major contributors in writing the manuscript. CR and ND performed cell transfection. HL 
and $\mathrm{CZ}$ performed statistical analysis. ZL and TM designed the study. All authors read and approved the final manuscript.

\section{Ethics approval and consent to participate}

The present study was approved by the Ethics Committee of Xi'an HongHui Hospital (Xi'an, China). Either the patients or their guardians provided written informed consent for participation in the study.

\section{Consent for publication}

The patient or their guardian provided written informed consent for the publication of any associated data.

\section{Competing interests}

The authors declare that they have no competing interests.

\section{References}

1. Duchman KR, Gao Y and Miller BJ: Prognostic factors for survival in patients with high-grade osteosarcoma using the surveillance, epidemiology, and end results (SEER) program database. Cancer Epidemiol 39: 593-599, 2015.

2. Ottaviani $\mathrm{G}$ and Jaffe N: The epidemiology of osteosarcoma. Cancer Treat Res 152: 3-13, 2009.

3. Maugg D, Rothenaigner I, Schorpp K, Potukuchi HK, Korsching E, Baumhoer D, Hadian K, Smida J and Nathrath M: New small molecules targeting apoptosis and cell viability in osteosarcoma. PLoS One 10: e0129058, 2015.

4. Ferguson WS and Goorin AM: Current treatment of osteosarcoma. Cancer Invest 19: 292-315, 2001.

5. Manley S, Williams JA and Ding WX: Role of p62/SQSTM1 in liver physiology and pathogenesis. Exp Biol Med (Maywood) 238 525-538, 2013

6. Moscat J and Diaz-Meco MT: p62 at the crossroads of autophagy, apoptosis, and cancer. Cell 137: 1001-1004, 2009.

7. Mizushima N, Levine B, Cuervo AM and Klionsky DJ: Autophagy fights disease through cellular self-digestion. Nature 451: 1069-1075, 2008

8. Inoue D, Suzuki T, Mitsuishi Y, Miki Y, Suzuki S, Sugawara S, Watanabe M, Sakurada A, Endo C, Uruno A, et al: Accumulation of p62/SQSTM1 is associated with poor prognosis in patients with lung adenocarcinoma. Cancer Sci 103: 760-766, 2012.

9. Luo RZ, Yuan ZY, Li M, Xi SY, Fu J and He J: Accumulation of p62 is associated with poor prognosis in patients with triple-negative breast cancer. Onco Targets Ther 6: 883-888, 2013.

10. Inui T, Chano T, Takikita-Suzuki M, Nishikawa M, Yamamoto G and Okabe $\mathrm{H}$ : Association of p62/SQSTM1 excess and oral carcinogenesis. PLoS One 8: e74398, 2013.

11. Burdelski C, Reiswich V, Hube-Magg C, Kluth M, Minner S, Koop C, Graefen M, Heinzer H, Tsourlakis MC, Wittmer C, et al: Cytoplasmic accumulation of sequestosome 1 (p62) is a predictor of biochemical recurrence, rapid tumor cell proliferation, and genomic instability in prostate cancer. Clin Cancer Res 21: 3471-3479, 2015.

12. Iwadate R, Inoue J, Tsuda H, Takano M, Furuya K, Hirasawa A, Aoki D and Inazawa J: High expression of p62 protein is associated with poor prognosis and aggressive phenotypes in endometrial cancer. Am J Pathol 185: 2523-2533, 2015.

13. Puissant A, Fenouille N and Auberger P: When autophagy meets cancer through p62/SQSTM1. Am J Cancer Res 2: 397-413, 2012.
14. Jawad MU and Scully SP: In brief: Classifications in brief: Enneking classification: Benign and malignant tumors of the musculoskeletal system. Clin Orthop Relat Res 468: 2000-2002, 2010.

15. Chen X, Yang TT, Wang W, Sun HH, Ma BA, Li CX, Ma Q, Yu Z and Fan QY: Establishment and characterization of human osteosarcoma cell lines with different pulmonary metastatic potentials. Cytotechnology 61: 37-44, 2009.

16. Lu Y, Guan GF, Chen J, Hu B, Sun C, Ma Q, Wen YH, Qiu XC and Zhou Y: Aberrant CXCR4 and $\beta$-catenin expression in osteosarcoma correlates with patient survival. Oncol Lett 10: 2123-2129, 2015.

17. Livak KJ and Schmittgen TD: Analysis of relative gene expression data using real-time quantitative PCR and the 2(-Delta Delta C(T)) method. Methods 25: 402-408, 2001.

18. Zhang Y, Ma Q, Liu T, Guan G, Zhang K, Chen J, Jia N, Yan S, Chen G, Liu S, et al: Interleukin-6 suppression reduces tumour self-seeding by circulating tumour cells in a human osteosarcoma nude mouse model. Oncotarget 7: 446-458, 2016.

19. Liu JL, Chen FF, Lung J, Lo CH, Lee FH, Lu YC and Hung CH: Prognostic significance of p62/SQSTM1 subcellular localization and LC3B in oral squamous cell carcinoma. Br J Cancer 111: 944-954, 2014.

20. Zhang J, Yang Z and Dong J: P62: An emerging oncotarget for osteolytic metastasis. J Bone Oncol 5: 30-37, 2016.

21. Mohamed A, Ayman A, Deniece J, Wang T, Kovach C, Siddiqui MT and Cohen C: P62/Ubiquitin IHC expression correlated with clinicopathologic parameters and outcome in gastrointestinal carcinomas. Front Oncol 5: 70, 2015.

22. Khan MM, Strack S, Wild F, Hanashima A, Gasch A, Brohm K, Reischl M, Carnio S, Labeit D, Sandri M, et al: Role of autophagy, SQSTM1, SH3GLB1, and TRIM63 in the turnover of nicotinic acetylcholine receptors. Autophagy 10: 123-136, 2014.

23. Bitto A, Lerner CA, Nacarelli T, Crowe E, Torres C and Sell C: P62/SQSTM1 at the interface of aging, autophagy, and disease. Age (Dordr) 36: 9626, 2014

24. Sahani MH, Itakura E and Mizushima N: Expression of the autophagy substrate SQSTM1/p62 is restored during prolonged starvation depending on transcriptional upregulation and autophagy-derived amino acids. Autophagy 10: 431-441, 2014.

25. Jain A, Lamark T, Sjøttem E, Larsen KB, Awuh JA, Øvervatn A, McMahon M, Hayes JD and Johansen T: p62/SQSTM1 is a target gene for transcription factor NRF2 and creates a positive feedback loop by inducing antioxidant response element-driven gene transcription. J Biol Chem 285: 22576-22591, 2010.

26. Mathew R, Karp CM, Beaudoin B, Vuong N, Chen G, Chen HY, Bray K, Reddy A, Bhanot G, Gelinas C, et al: Autophagy suppresses tumorigenesis through elimination of p62. Cell 137: 1062-1075, 2009

27. Hayes JD and McMahon M: NRF2 and KEAP1 mutations: Permanent activation of an adaptive response in cancer. Trends Biochem Sci 34: 176-188, 2009.

28. Hydbring P, Malumbres M and Sicinski P: Non-canonical functions of cell cycle cyclins and cyclin-dependent kinases. Nat Rev Mol Cell Biol 17: 280-292, 2016.

29. Hirai H and Nakatsuru Y: Evaluating chemical CDK inhibitors as cell death inducers. Methods Mol Biol 1336: 167-178, 2016.

30. Linares JF, Amanchy R, Greis K, Diaz-Meco MT and Moscat J: Phosphorylation of p62 by cdk 1 controls the timely transit of cells through mitosis and tumor cell proliferation. Mol Cell Biol 31: 105-117, 2011.

31. Duran A, Amanchy R, Linares JF, Joshi J, Abu-Baker S, Porollo A, Hansen M, Moscat J and Diaz-Meco MT: p62 is a key regulator of nutrient sensing in the mTORC1 pathway. Mol Cell 44: 134-146, 2011.

This work is licensed under a Creative Commons Attribution-NonCommercial-NoDerivatives 4.0 International (CC BY-NC-ND 4.0) License. 